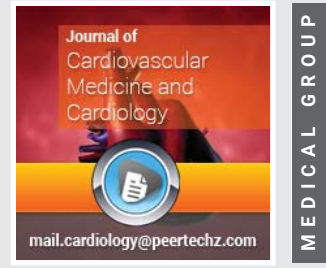

\title{
Human umbilical cord blood derived mesenchymal cells for the treatment of myocardial infarction in rat model
}

\section{Ayapati Gautam Mehdi ${ }^{1,4}$, Vikram Aiman Ayapati ${ }^{1}$, Avinash B ${ }^{6}$,} A. A. Khan ${ }^{6}$, Nirmal Kumar Lohiya ${ }^{2}$, Dharma Rakshak Ayapati ${ }^{3}$, Roya Rozati ${ }^{1,5}$

1MHRT Hospital and Research Centre, 8-2-120/86/1A Road No \#3, Banjarahills, Hyderabad-500 034 ,

Telangana, India

2Department of Zoology, University of Rajasthan, Jaipur, Rajasthan, India

3Apollo Hospital, Secunderabad, Telangana, India

4Jaipur National University, Jaipur-302 004, Rajasthan, India

5Professor and Unit chief II, Department of Obstetrics and Gynecology, Shadan Institute of Medical

Sciences, Hyderabad, Telangana, India

6Central Research Laboratory, CLRD, Hyderabad, Telangana, India

Received: 19 March, 2020

Accepted: 25 April, 2020

Published: 27 April, 2020

*Corresponding author: Dr. Roya Rozati, MHRT Hospital and Research Centre, 8-2-120/86/1A Road No \#3, Banjarahills, Hyderabad-500 034, Telangana, India, Tel: 040-23552525; E-mail: drroyarozati@gmail.com

https://www.peertechz.com

\section{Check for updates}

\section{Abstract}

Objectives: The present study was designed to know the possible protective and regenerative effects of human Umbilical Cord Blood (UCB) derived MSCs in Myocardia Infarction (MI) in rat model using Isoproterenol administration.

Material \& methods: Isoproterenol injection was given subcutaneously for 2 days to induce MI in rat model. After development of MI various blood and tissue parameters were assessed sich as urea, creatinine, SGOT, SGPT, troponin I, Lactic Dehydrogenase (LDH) and Creatine Kinase (CK). Treatment was given by single dose of MSCs. After treatment period all the parameters were assessed again and comparison were done before and after treatment.

Results: After development of MI all the biochemical parameters were elevated. MSC transplantation, performed when MI have already developed, showed better results. It inhibits the degradation of normal collagen and the formation of poorly cross-linked collagens, resulting in attenuation of MI and improvement of heart function by means of troponin I, Lactic Dehydrogenase (LDH) and Creatine Kinase (CK) level. In addition, this impact is not instantaneous but is persistent for at least 90 days, supporting the role of MSC transplantation.

Conclusion: Our data suggested that transplantation of MSCs in MI model has improved the cardiac function. Till now, there is no evidence attributing this improvement to regeneration and other paracrine mechanisms are also believed to contribute in the improvement of cardiac function.

\section{Introduction}

Mesenchymal Stem Cells (MSCs) have raised immense hopes for their vast applications in regenerative medicine [1,2]. It has paved its way to a large number of clinical trials for a broad range of diseases. So far, several studies have provided promising results, but more research is required for their further validation due to varying outcomes [3]. This might be due to varying sources of cells, heterogeneity in MSCs cultures and absence of reliable protocols for isolation and enrichment of the naïve stem cell fraction. MSCs can be isolated from many tissues under different culture conditions but appropriate cell source is needed to be investigated for their efficient applications in clinical practice.

Cardio Vascular Disease (CVD) is the foremost reason of 
morbidity and mortality [4]. Progression and development of myocardial infarction and is a primary cause for heart failure [5]. Present therapeutically strategies to treat infracted heart and consequent heart failure comprise drugs ( $\beta$-blockers and angiotensin, aspirin converting enzyme inhibitors), thrombolytic therapy, angioplasty, heart transplantation and ventricular assist devices [6]. The relative incidence and death occurring due to MI are significantly increasing. As a result there is a need to identify novel therapeutic strategies. Myocardial Infarction (MI), in general considered as a heart attack, which occurs due to reduced blood flow or stopping of blood flow to a portion of heart that results in heart muscle damage [7]

Coronary stent implantation, thrombolysis, coronary artery bypass grafting and pharmacotherapy are in current clinical use for treating MI to further enhance patients' survival. However these treatments couldn't able to meet up the fundamental requirements need to repair the injured heart and failed to restore the heart function. In these condition advances in regenerative medicine using stem cells has raised a scope for treating MI. Recently stem cell transplantation has showed a noteworthy evolution in preclinical as well as in clinical studies.

The potential usefulness of UCB derived stem cells is can be opted in preclinical settings due to readily available source, multipotent nature, immunologically naive and minimal ethical concerns. The success of this therapeutic strategy in preclinical models will facilitate the production and clinical applicability which has tremendous potential to save millions of lives each year with further understanding.

The present study was designed to know the possible protective and regenerative effects of human Umbilical Cord Blood (UCB) derived MSCs in Myocardia Infarction (MI) in rat model using Isoproterenol administration.

\section{Materials \& methods}

\section{Ethical approval}

The study protocol was approved by the Institutional Ethics Committee, Medical Health \& Research Trust, Banjarahills Hyderabad, India. Umbilical Cord Blood (UCB) was collected from Medical Health \& Research Trust after taking signed informed consent forms all the patients.

\section{Collection of UCB}

A total of 5 UCB samples were collected during cesarean under sterile conditions.

\section{Isolation, characterization and enumeration of MSCs}

Isolation, characterization and enumeration of MSCs were done based on previous study [8].

\section{Animal ethics committee}

All the animal experiments were carried out based on the guidelines of the Animal Ethics committee, Committee for the Purpose of Control and Supervision of Experiments on Animals
(CPCSEA), and approval were obtained from the Animal Ethical Committee.

Different groups in myocardial infarction (MI) in rat model

1. Group I: Healthy controls $(n=10)$ (Control Group)

2. Group II: Isoproterenol induced myocardial infarction in normal rats $(\mathrm{n}=10)$ (MI Group)

3. Group III: hUCB-MSCs transplantation once in rats with myocardial infarction ( $\mathrm{n}=10)(\mathrm{MI}+$ MSCs)

\section{Experimentation environment}

In the present investigation, male wister rats, weighing 150-200g in average, were used. $\mathrm{Al}$ the rats were kept in cages and housed in facilities with the temperature of $24 \pm 2^{\circ} \mathrm{C}$. All the rats were monitored with alternating dark/light cycle at every 12 hours. All the animals were fed specific diet use in laboratories.

\section{Infarction induction}

The myocardial infarction was induction in the Group II. Isoproterenol (IP) was injected through subcutaneous injection at a dose of $85 \mathrm{mg} / \mathrm{kg} /$ day. Isoproterenol was diluted in $2 \mathrm{ml}$ of saline and injected. The injection was given for two consecutive days with gap of 24 hours between applications.

\section{Animal sacrifice}

Animal were sacrificed from the each group after the development of MI. Animals were sacrificed after the transplantation of MSCs on day 15, 30, 45 and 60. After that the reaming rats were followed up for 90 day.

\section{Catalase and glutathion estimation}

Catalase and Glutathion estimation were estimated before the development of MI, after development of MI and after the transplantation of MSCs

\section{Biochemical parameters analysis}

Biochemical parameters such as urea, creatinine, SGOT, SGPT, troponin I, Lactic Dehydrogenase (LDH) and Creatine Kinase (CK) were also assessed in all the groups.

\section{Mesenchymal Stem cell transplantation}

The rats after MI group III and IV were chosen to receive hMSCs therapy. Group III received the single dose of MSCs and group IV received two doses of MSCs. First dose of MSCs were given after the development of MI and another dose of cells were given after 15 days for group IV. $1 \times 10^{6}$ culture-expanded hMSCs suspended in $50 \mu \mathrm{L}$ of normal saline were injected intramyocardially at the left anterior free wall by using an insulin syringe with a 30-gauge needle. hMSCs were injected over a period of 5-10 seconds at three separate sites. The injected sites were chosen to be at least $5 \mathrm{~mm}$ away from the left ventricular apex.

Citation: Mehdi AG, Ayapati VA, Avinash B, Khan AA, Rozatiet R, et al. (2020) Human umbilical cord blood derived mesenchymal cells for the treatment of myocardial infarction in rat model. J Cardiovasc Med Cardiol 7(2): 079-085. DOI: https://dx.doi.org/10.17352/2455-2976.000117 


\section{Molecular analysis using RT-qPCR}

Tests focusing on particular mRNAs are the most broadly utilized alternate choices for molecular examination of MI. Numerous genes are expressed at low level in normal cells, however, elevated expression is observed throughout MI. Quantifying of their expression levels using RT-qPCR can set the cut-off for precise characterization of MI. For molecular analysis of MI, total RNA was isolated from heart tissue. RNA was quantified by nanodrop reading and further used for cDNA synthesis.

\section{Results}

\section{Enrichment and characterization of human UCB-MSCs}

Cultured cells were changed their morphology from spherical to spindle shape from day1 to day 14 . The cells were starting adhere on petri-plate at day 3 and changed their morphology completely at day 14 (Figure 1) [8].

\section{ICC staining of human UCB-MSCs using CD90-FITC at day 14}

Cultured UCB-MSCs were stained with positive mesenchymal marker CD90-FITC. We observed most of the cells showed positive staining for CD90 (Figure 2). The fibroblast or spindle shaped phenotype of cells flourished in green with intracellular staining of CD90 [8].

\section{Myocardial infarction model development}

The establishment of MI animal model was determined by estimating haematological, biochemical and enzymatic parameters along with histological analysis of heart tissues. Mortality was estimated to be more than $25 \%$ in $\mathrm{MI}$ animal models whereas no mortality was observed in control group.

\section{Changes in haematological parameters after IP injection}

Twenty-four hours after the last administration, blood samples were drawn from all the rats and used for estimation of haematological changes. During correlation between control and infracted animal groups for haematological parameters, we didn't observe any significant difference in haemoglobin levels ( $p>0.05$ ) (Figure 3A) whereas significantly increased levels were observed for leukocyte (Figure $3 \mathrm{~B}$ ) and neutrophil counts ( $\mathrm{p}>0.001$ ) (Figure $3 \mathrm{C}$ ).

\section{Biochemical Changes after IP injection}

Quantification of biochemical parameters after IP injection showed significant increase in biochemical parameters such as ALT, AST and urea $(p<0.0001)$ in infracted group as compared to control group (Figures $4 \mathrm{~A}, \mathrm{~B}$ and D). Similarly significant increase in LDH levels were also observed in infracted group as compared with the control $(p<0.0001)$ (Figure $4 \mathrm{C})$. Whereas no significant change in creatinine levels were observed in infracted group with respect to control ( $p>0.05)$ (Figure $4 \mathrm{E}$ ).

\section{Changes in tropinin-I and creatine kinase (CK) during $\mathrm{MI}$ model development}

Quantitative estimation of cardiac markers such as tropinin-I and CK in animal sera showed significantly increased levels in IP-induced infracted group as compared to the healthy controls $(\mathrm{p}<0.001)$ (Figure 5A and 5B).

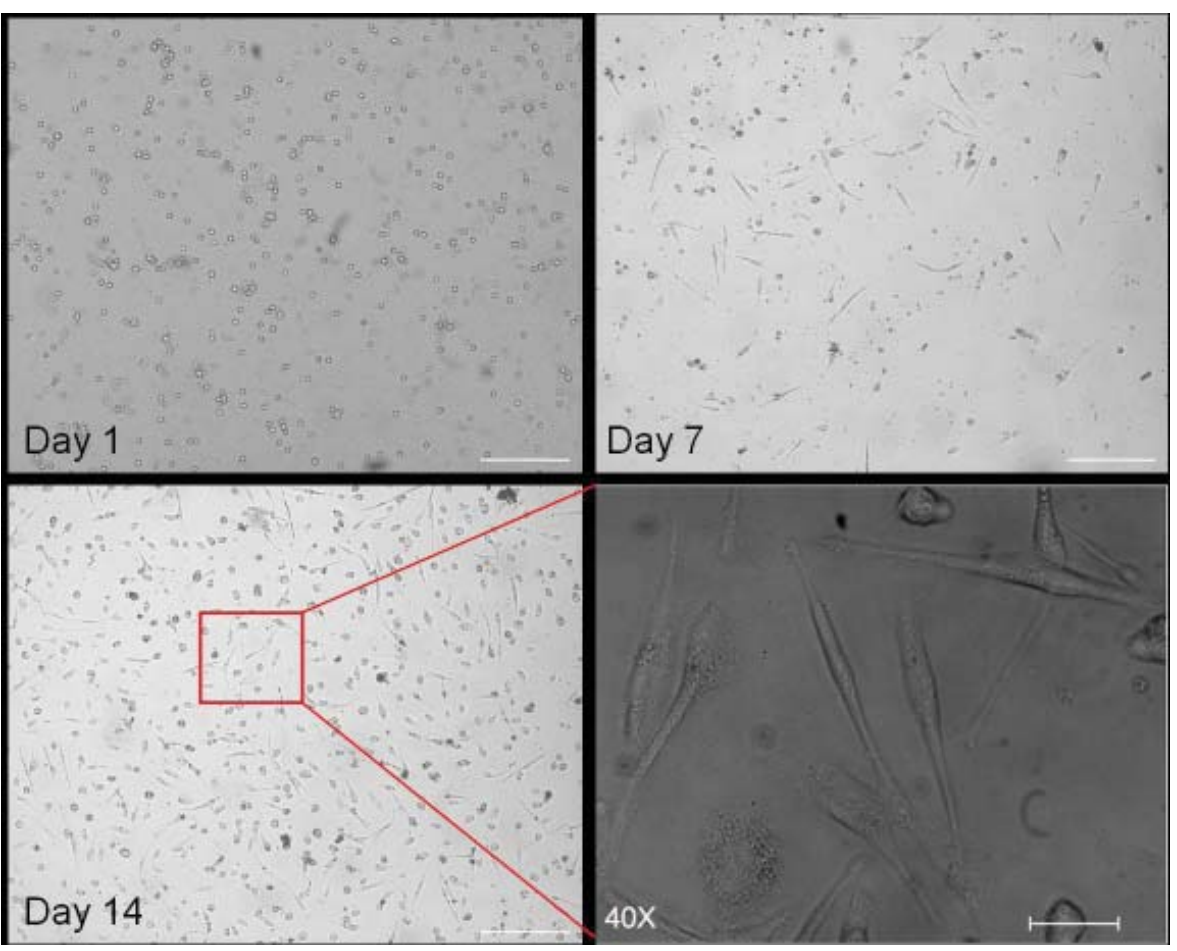

Figure 1: Proliferating human UCB-MSCs (A) Day 1 (upper left panel) MNCs, (B) Day 7 (upper right panel) proliferating MSCs, (c) Day 14 (lower left panel) confluent MSCs, (D) Day 14 (lower right panel) proliferating MSCs under higher resolution (40X: magnifications) [8]

Citation: Mehdi AG, Ayapati VA, Avinash B, Khan AA, Rozatiet R, et al. (2020) Human umbilical cord blood derived mesenchymal cells for the treatment of myocardial infarction in rat model. J Cardiovasc Med Cardiol 7(2): 079-085. DOI: https://dx.doi.org/10.17352/2455-2976.000117 


\section{Changes in cardiac enzymes during MI model develop- ment}

Changes in cardiac functional enzymes such as catalase and glutathione was quantified in infracted animals and compared with the controls. The quantitative data showed significantly reduced activity of cardiac catalases after IP injection $(p<0.0001)$ (Figure 6A). Another key cardiac functional marker glutathione level was also significantly reduced in infracted group $(p<0.001)$ (Figure 6B).

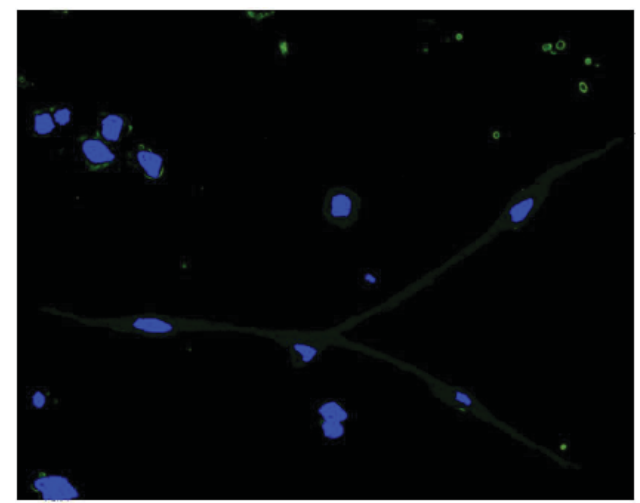

Figure 2: ICC staining for proliferating cells as monolayer at Day 14 . Spindle shaped structure was stained with CD90-FITC showing morphology of MSCs [8].
(A)

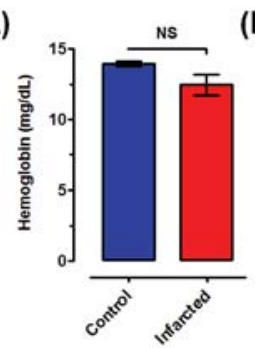

(B)

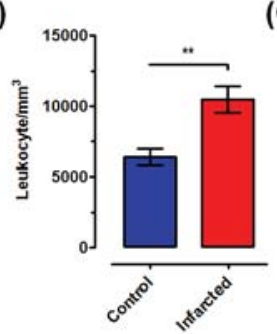

(C)

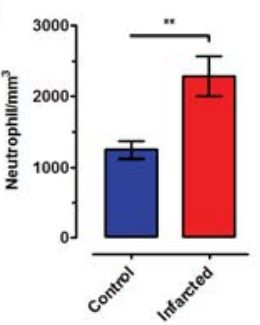

Figure 3: Quantitative estimation of haematological parameters in IP infracted group as compared to controls (NS: non-significant, i. e. $p>0.05,{ }^{* \star} p<0.001$ ).
(A)

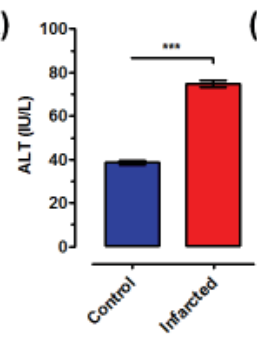

(B)
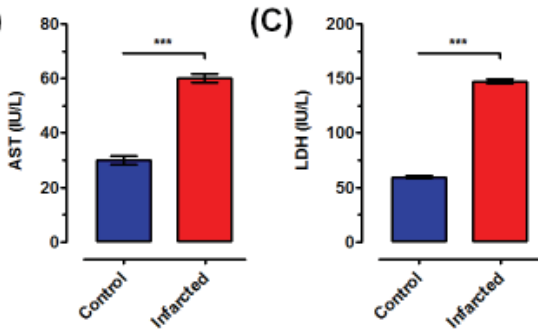

(D)
(E)

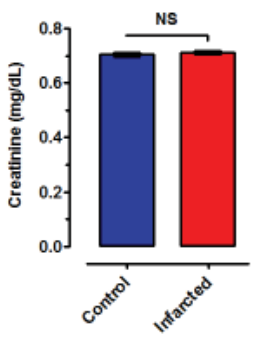

(A)

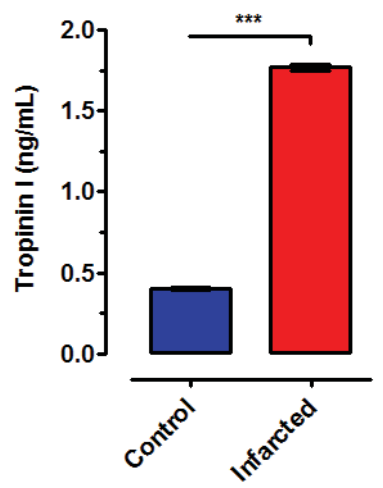

(B)

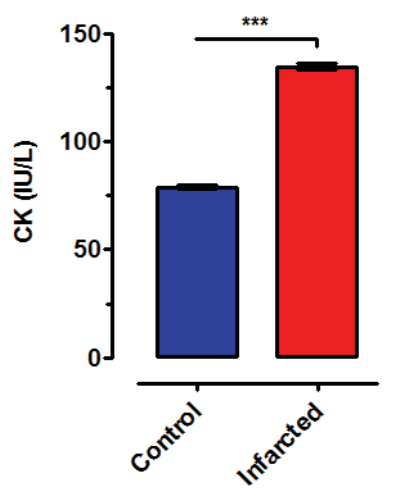

Figure 5: Quantitative estimation of serum tropinin-I and CK in IP infracted group as compared to controls $(* * * p<0.0001)$
(A)

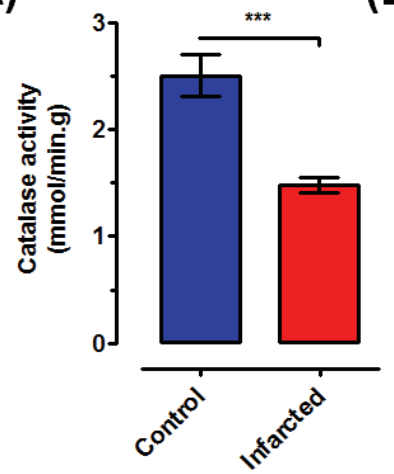

(B)

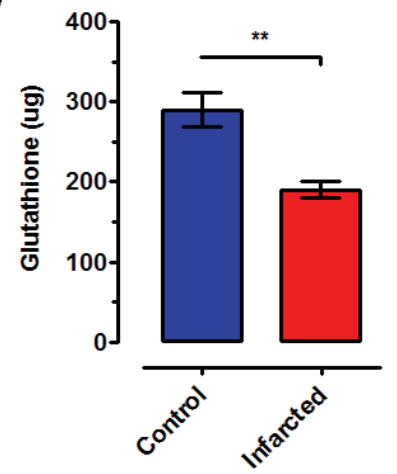

Figure 6: Quantification of catalase activity and glutathione in ISO infracted group showing significant reduction as compared to control group (**p $<0.001,{ }^{\star \star \star} p<$ 0.0001).

\section{Changes in haematological parameters after single dose MSCs transplantation in animals with MI}

Transplantation of single dose of MSCs in MI models didn't show significant change in haemoglobin levels as compared to MI group with the time duration up to 90 days post-transplantation ( $p>0.05$, NS: non-significant) (Figure $7 A)$. Leukocytes numbers were significantly reduced in treated group with increasing time compare with non-treated gropu (Figure 7B). Furthermore neutrophil count was reduced significantly at day 90 post-transplantation compare to non treated group. (Figure 7C).

\section{Changes in serum levels of biochemical parameters af-} ter single dose MSCs transplantation in animals with MI

The biochemical parameters post-transplantation of MSCs showed significant reduction in ALT (Figure 8A), AST (Figure $8 \mathrm{~B}), \mathrm{LDH}$ (Figure 8C) and urea (Figure 8D) was increasing with time of transplantation increases compare with non treated group. The level was observed near to control group. However no significant difference was observed for creatinine posttransplantation ( $p>0.05$ ) compare to non treated group (Figure $8 \mathrm{E}$ ). The normalization of serum urea level was observed after 
day 60 (Figure 8D). In contrast to other biochemical parameters serum creatinine levels didn't show significant variation after MSCs transplantation in MI models as compared to the other group (Figure $8 \mathrm{E}$ ).
(A)

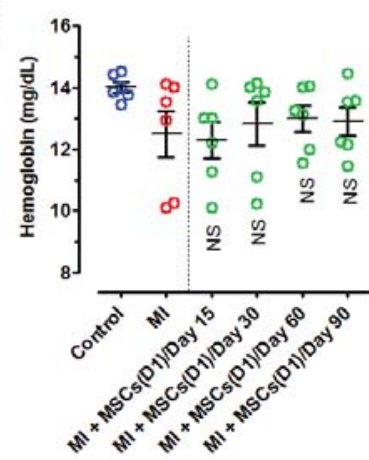

(B)

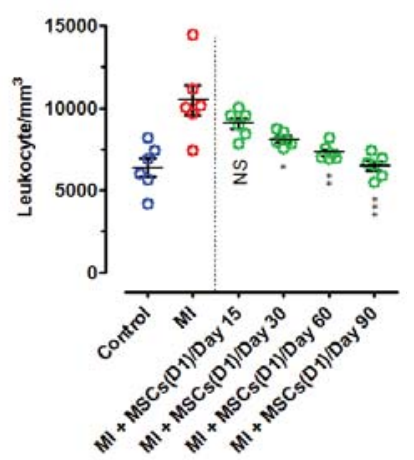

(C)

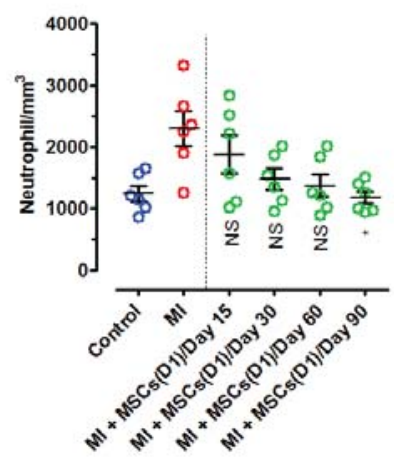

Figure 7: Changes in haematological parameters pre and post-transplantation of MSCs in MI animal models in time dependent manner (NS: non-significant, ${ }^{*} \mathrm{p}<0.01$, $\left.{ }^{* *} p<0.001,{ }^{* * *} p<0.0001\right)$.

\section{Changes in tropinin-I and CK level after single dose MSCs transplantation in animals with MI}

The significant reduced levels of troponine were observed from day 30 to day 90 in treated group (Figure 9A). The CK level was significantly reduced from day 15 to day 90 as compared to MI group after single dose of MSCs transplantation (Figure 9B). There was no significant changes observed in control and treated group.

\section{Changes in cardiac specific functional markers after single dose MSCs transplantation in animals with MI}

Cardiac specific functional markers such as catalase showed significant increase after 90 days of MSCs transplantation, whereas no significant change was observed at earlier time points (Figure 10A) compare to non treated group. Similarly glutathione levels were also increased at day 60 and day 90 after MSCs transplantation with respect to MI group (Figure $10 B)$. There were no significant difference in control and treated group at day 90 .

\section{Discussion}

CVD is the foremost cause of morbidity and mortality in patients suffering with diabetes [9-11]. Advancement and progression of MI may lead to heart failure which is much more complex and multifactorial. MI is a trademark of various heart diseases and reflected as a chief factor in the evolution of heart failure. CVD accounted for less than $10 \%$ of all deaths worldwide at the commencement of the $20^{\text {th }}$ century. But at the foundation of the $21^{\text {st }}$ century, CVD accounted for nearly half of all deaths in the developed world and $25 \%$ in developing world. Thus, preclusion of MI is a serious goal in the treatment
(A)

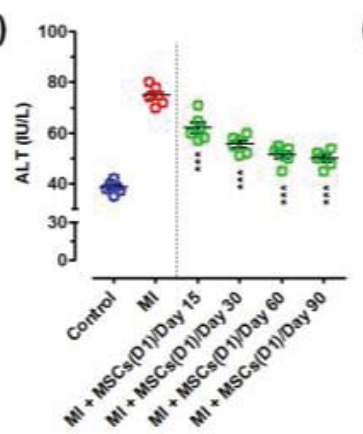

(B)

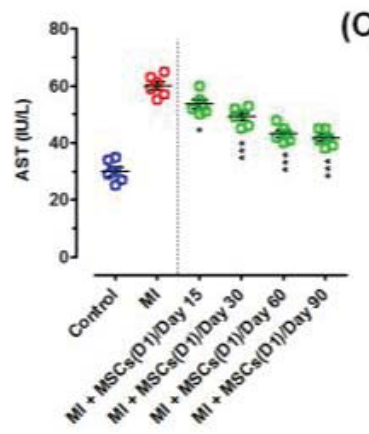

(C)

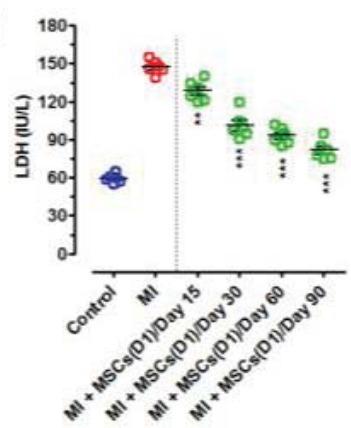

(D)

(E)
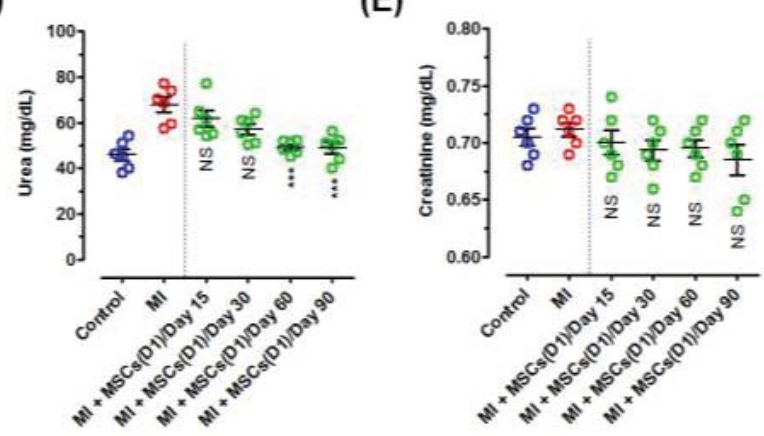
(A)

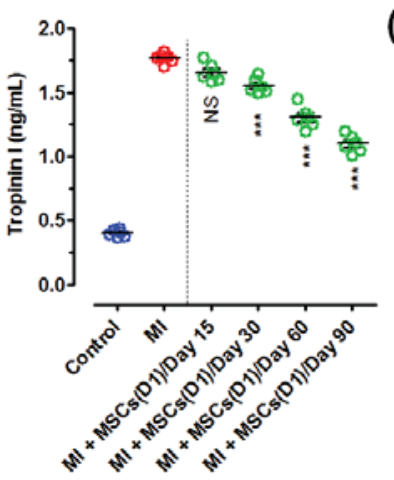

(B)

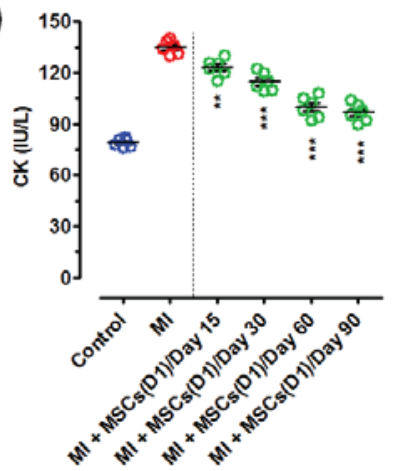

Figure 9: Changes in tropinin-I and CK levels in Ml rats before and after transplantation of human MSCs in time dependent manner (NS: non-significant, $\left.{ }^{* *} p<0.001,{ }^{* * *} p<0.0001\right)$
(A)

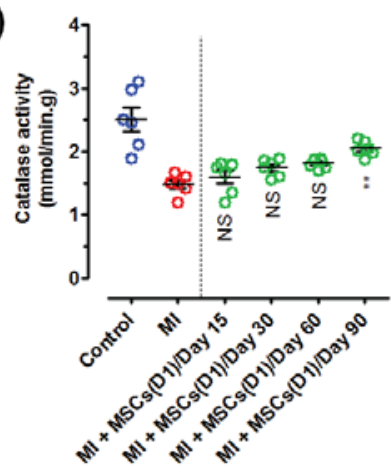

(B)

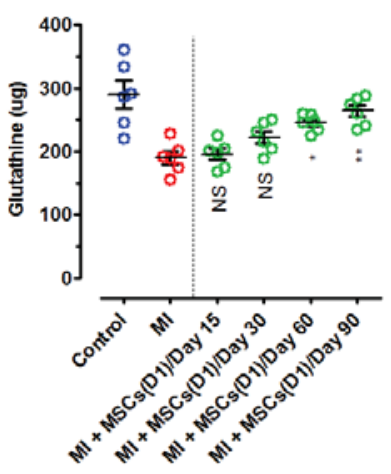

Figure 10: Changes in catalase activity and glutathione levels in MI rats before and after transplantation of human MSCs in time dependent manner (NS: nonsignificant, $\left.{ }^{*} p<0.01,{ }^{* *} p<0.001\right)$.

of heart failure and the degree of myocardial fibrosis are key factors of rejoinder to treatment and prognosis in a several cardiac conditions.

Our study has demonstrated that the model of MI induced by isoproterenol was appropriately authenticated, given that the comparison between normal and infarction groups. Subcutaneous administration of isoproterenol caused mortality, caused an increase of myocardial injury. UCB derived MSCs were injected in rat model of isoproterenol-induced MI.

Our study has demonstrated that the model of MI induced by isoproterenol was appropriately authenticated, given that the comparison between normal and infarction groups. Subcutaneous administration of isoproterenol caused mortality caused an increase of myocardial injury.

UCB derived MSCs were injected in rat model of isoproterenol-induced MI. These rats were subdivided into 3 groups. Group I was served as control. In group II, MI were developed by induction of isoproterenol but no treatment were given for them and they were sacrifice in all the time intervals. In group III rats were induced with isoproterenol to develop the MI model and were treated with only single dose of MSCs. First dose of MSCs was give after the development of MI.

Several biochemical markers were elevated before and after the induction of IP. ALT, AST, troponin I and other hematological parameters were also elevated such as increased in leukocyte and neutrophil counts and concentrations of urea. After the development of MI model using the induction of IP several enzyme activity were reduced such as catalase and glutathione concentrations in myocardial tissue and induced histopathological changes such as inflammation, myofibril degeneration and necrosis. Regarding mortality, the subsequent data from the study showed a mortality of $25 \%$ in the MI group. This value is consistent with data reported by several other investigators, pointing to the isoproterenolinduced myocardial infarction as a cause of mortality in this experimental model. Acikel et al. 2005 [12], reported a mortality rate of $33.33 \%$ in rats undergone administration of isoproterenol, the approximate value found in this research.

Our study has shown that after twenty-four hours after the last administration, blood samples were drawn from all the rats and used for estimation of haematological changes. During correlation between control and infracted animal groups for haematological parameters, we didn't observe any significant difference in haemoglobin levels ( $p>0.05)$.

The effect of isoproterenol administration on the levels of hemoglobin is underreported in the literature. Sangeetha \& Quine [13], reported that an increase in erythrocyte count and hemoglobin concentrations in rats' undergone isoproterenolinduced MI. Our study demonstrated that the administration of isoproterenol caused an increase in leukocyte counts and neutrophils in the infarcted group, when compared to other group. High counts of leukocytes and neutrophils were also reported in rats with isoproterenol-induced myocardial infarction [13] and are deliberated at risk for the development of MI [14]. Friedman, et al. [15], were the first to report that the association between neutrophil count and the consequent progress of MI. In MI, neutrophils may contribute to myocardial injury due to the release of leukotrienes, ROS and hydrolytic enzymes. The degree of leukocytosis may also be associated with the magnitude of myocardial necrosis [12].

Our study demonstrated that transplantation of single dose of MSCs in MI animal models didn't show significant change in haemoglobin levels as compared to MI group with the time duration up to 90 days post-transplantation. While the number of leukocytes significantly reduced consistently with increasing the post- transplantation time. Furthermore neutrophil count was reduced significantly at day 90 post-transplantation whereas no significant change was observed in early time points (day 15 to day 60) post-transplantation. Comparative analysis of haematological parameters such Haemoglobin levels, Leukocytes and Neutrophil counts as for one and two dose MSCs transplantation effects on infracted animal models didn't show any significant difference with the time.

The results obtained from animal studies are promising and encouraging. The inconsistencies and diversity in results found to date redirect the ongoing research focus, the encounters that exist in this developing field, and the difficulties that must be dazed in order for the use of stem cell therapy in cardiovascular medicine to comprehend its impending. Forthcoming research 
should target to grow more consistent techniques so that results are analogous, and supplementary clinical trials are desirable in mandate to authenticate and build on earlier findings.

\section{References}

1. Jiang $Y$, Jahagirdar BN, Reinhardt RL, Schwartz RE, et al. (2002) Pluripotency of mesenchymal stem cells derived from adult marrow. Nature 418: 41-49. Link: https://bit.ly/355hQJ2

2. Caplan Al (2007) Adult mesenchymal stem cells for tissue engineering versus regenerative medicine. J Cell Physiol 213: 341-347. Link: https://bit.ly/2XZWsDE

3. Gluckman E, Ruggeri A, Volt F, Cunha R, Boudjedir K, et al. (2011) Milestones in umbilical cord blood transplantation. $\mathrm{Br} \mathrm{J}$ Haematol 154: 441-447. Link: https://bit.ly/3cLGFfH

4. Finegold JA, Asaria P, Francis DP (2013) Mortality from ischaemic heart disease by country, region, and age: Statistics from World Health Organization and United Nations. Int J Cardiol 168: 934-945 Link: https://bit.ly/3axiBM8

5. Faiella W, Atoui R (2016) Therapeutic use of stem cells for cardiovascular disease. Clin Trans Med 5: 34 Link: https://bit.ly/2zxQ8ct

6. Thygesen K, Alpert JS, Jaffe AS, Simoons ML, Chaitman BR, et al. (2012) Third universal definition of myocardial infarction. Eur Heart J 33: 2551-2567 Link: https://bit.ly/3cPQ4mH

7. Eltyeb A, Tomasz S, Guarita-Souza LC, Teixeira de Carvalho KA, Gallo P, et al. (2011) Stem cell therapy in heart diseases: a review of selected new perspectives, practical considerations and clinical applications. Curr Cardiol Rev 7: 201-212 Link: https://bit.ly/3eMaGxQ
8. Mehdi AG, Ayapati VA, Choudry VS, Reddy VN, Surror AU, et al. (2018) Human Umbilical Cord Blood: A Potential Source for Mesenchymal Stem Cells. Int J Sci Res 7: 641-644

9. Benjamin EJ, Virani SS, Callaway CW, Chamberlain AM, Chang AR, et al. (2018) Heart Disease and Stroke Statistics-2018 Update: A Report From the American Heart Association. Circulation 137: e67-e492. Link: https://bit.ly/3cQL9Sb

10. Scarborough P, Bhatnagar P, Wickramasinghe K, Smolina K, et al. (2010) Coronary heart disease statistics 2010. In British Heart Foundation heart statistics publications. British Heart Foundation.

11. Lloyd-Jones D, Adams RJ, Brown TM, Carnethon M, Dai S, et al. (2010) 644 Heart disease and stroke statistics -2010 update: a report from the American 645 Heart Association. Circulation 121: e46-e215. Link: https://bit.ly/2yEYXR8

12. Acikel M, Buyukokuroglu M. E, Erdogan F, Aksoy H, Bozkurt E, et al. (2005) Protective effects of dantrolene against myocardial injury induced by isoproterenol in rats: biochemical and histological findings. Int J Cardiol 98: 389-394. Link: https://bit.ly/2S7LHLB

13. Sangeetha T, Quine SD (2008) Protective effect of S-allyl cysteine sulphoxide (alliin) on glycoproteins and hematology in isoproterenol induced myocardial infarction in male Wistar rats. J Appl Toxicol 28: 710-716. Link: https://bit.ly/2Y1jCJP

14. Burr ML, Holliday RM, Fehily AM, Whitehead PJ (1992) Hematological prognostic indices after myocardial infarction: evidence from the diet and reinfarction trial (DART). Eur Heart J 13: 166-170. Link: https://bit.ly/2xc1CS2

15. Friedman GD, Tekawa I, Grimm RH, Manolio T, Shannon SG, et al. (1990) The leucocyte count: correlates and relationship to coronary risk factors: the CARDIA study. Int J Epidemiol 19: 889-893. Link: https://bit.ly/3bClexH

\section{Discover a bigger Impact and Visibility of your article publication with} Peertechz Publications

\section{Highlights}

* Signatory publisher of ORCID

- Signatory Publisher of DORA (San Francisco Declaration on Research Assessment)

* Articles archived in worlds' renowned service providers such as Portico, CNKI, AGRIS, TDNet, Base (Bielefeld University Library), CrossRef, Scilit, J-Gate etc

* Journals indexed in ICMJE, SHERPA/ROMEO, Google Scholar etc.

* OAI-PMH (Open Archives Initiative Protocol for Metadata Harvesting)

* Dedicated Editorial Board for every journal

* Accurate and rapid peer-review process

* Increased citations of published articles through promotions

* Reduced timeline for article publication

Submit your articles and experience a new surge in publication services (https://www.peertechz.com/submission).

Peertechz journals wishes everlasting success in your every endeavours.

Copyright: @ 2020 Mehdi AG, et al. This is an open-access article distributed under the terms of the Creative Commons Attribution License, which permits unrestricted use distribution, and reproduction in any medium, provided the original author and source are credited.

Citation: Mehdi AG, Ayapati VA, Avinash B, Khan AA, Rozatiet R, et al. (2020) Human umbilical cord blood derived mesenchymal cells for the treatment of myocardial infarction in rat model. J Cardiovasc Med Cardiol 7(2): 079-085. DOI: https://dx.doi.org/10.17352/2455-2976.000117 